\title{
Supporting organizational change: fostering a more flexible approach to course delivery
}

\author{
Gail Hart, Yoni Ryan and Kerry Bagdon \\ Teaching and Learning Support Services, Queensland University of Technology, \\ email:g.hart@qutedu.au
}

Queensland University of Technology (QUT) adopted a flexible delivery policy in 1996. The main objective of the policy was to develop a more student-centred approach to teaching and learning, since QUT's student population is predominantly part-time, 'mature age', already in employment, and very diverse in cultural and academic background. For many staff, the policy was threatening: staff were uncertain where they might begin to adapt their traditional face-to-face teaching approaches to overcome the limitations associated with time and place, and they were fearful that their teaching role and academic expertise might be superseded by a technological alternative. They lacked confidence to incorporate appropriate and relevant technologies in an innovative and effective way to support student learning objectives. This paper focuses on the implementation of QUT's policy. It highlights the role of a central services department, Teaching and Learning Support Services (TALSS), in providing training and fostering cultural change across the university. The implementation was guided by a model of flexible education and $a$ set of principles underpinning $a$ 'whole of organization' approach to flexible delivery. Strategies for supporting innovators, sharing experience across disciplines, co-ordinating and focusing the support of educational developers, and embedding staff development processes are outlined. The success and limitations of the organizational change strategy are summarized as 'lessons learned' to inform ongoing institutional policy and procedures.

\section{Organizational contexts}

In Australia, as in the UK, the political, economic and technological contexts within which higher education operates are shifting. Many commentators (e.g. Tiffin and Rajasingham, 1995; Oblinger and Rush, 1997) have predicted that the outcomes for teaching and learning environments will be as shattering to the 'bricks and mortar' universities as the longpredicted tectonic plate shift which will swallow San Francisco. 
Our vision is less apocalyptic. Indeed, we are convinced from various research projects in which we have participated (Hart et al., 1998; Cunningham et al., 1998) that the move to student-centred education, if it is genuinely embraced by universities, will result in a slow evolution of existing university environments.

However, there is no doubt that the last decade has already produced many changes within universities worldwide. Classes are larger, student populations more diverse, both culturally and in terms of their preparation for independent learning. With the introduction of tuition fees and supplementary charges for support services such as computer access, students are becoming more discerning 'consumers'. They expect high-quality learning opportunities and better ancillary services. At the same time, public funding has been reduced as governments of mature economies seek to reduce their outlays by privatizing as many of their traditional services as possible. Tertiary education has become a victim of its own success: in moving from an elite to a mass system, it has ceased to become a public investment by the community in its collective future, and has become a 'private good' (cf. Saul, 1997) requiring economic decisions as to its worth to individual students.

Whether we view these changes with delight or dismay, the reality is that we must respond energetically and responsibly to ensure that we continue to foster optimum learning outcomes for our students. Much of the burden of this work falls upon individual academics. But the organizational culture within which teaching and learning occurs plays an increasingly important role in teaching, for several reasons:

- the increasing use of technology in the delivery of learning materials means that institutions have new challenges, e.g. in the provision and/or co-ordination of computer facilities, to ensure access and equity prevail;

- individual academics cannot master alone the intricacies of technology-aided communication;

- communication technologies are changing the nature of personal interactions, with less need for face-to-face communication to resolve course enquiries or provide individualized advice.

Analysis of QUT's student population in the late 1990s revealed a changed demographic to predominantly part-time and mature-age students. Students are attracted to QUT because of its strong industry and professional links, high rates of graduate employment, and reputation for applied research. Such a population seemed to demand more flexible administrative and teaching approaches that could accommodate their part-time status, and their need for highly relevant professional qualifications. QUT is also a multi-campus institution with three campuses in the northern suburbs of Brisbane, creating consequent travel difficulties for staff and students who operate across campuses. Hence the university determined to investigate and if necessary 're-engineer' its structure to accommodate changing student needs and better prepare students for their professional futures. It was recognized that cultural change was integral to any systemic change, as both Bates (1995) and Mason (1998) argue.

The term 'flexible delivery' is now widely used in Australia to describe an educational approach that takes advantage of technology and new procedures (such as automated telephone or online enrolment) to allow students more choice in relation to the time and 
place of their study experiences, and to bring greater efficiencies to an organization's administrative practices. QUT introduced a flexible delivery policy in 1996.

However, the launch of the policy prompted real concern amongst our staff. It coincided with the first round of job losses in Australian universities and was linked with potential staff retrenchments. The emphasis on unfamiliar technologies alienated staff who were committed to face-to-face teaching, and who feared their hard-won discipline expertise would be de-valued in what they perceived to be an inevitable 'online university'. Our staff are not alone: University of Washington staff, USA, have protested strongly against the 'de-humanization' of teaching via online courses (The Industry Standard, 12 June 1998, at $\mathrm{ttp} / / / \mathrm{www}$. thestandard.net/articles/news_display/0,1270,670,00.html).

However, changing practice was perceived as an imperative at QUT, in order to maintain a competitive edge in the higher education sector and in response to the demands of an increasingly discerning student body. The task facing the institution's management was to develop:

- an organizational climate which diminished fear and encouraged appropriate change;

- a support structure which built on staff strengths, and involved staff in devising their own solutions to the problems of the external environment and the needs of their students;

- a robust system, which could accommodate upgrades, software changes, and increasing bandwidth demands, as well as legal changes;

- a support unit that provided the physical infrastructure and the initial/ongoing technical advice, and specialist academic development staff who could bridge the divide between the 'techos' and the teachers.

\section{A model of flexibility in tertiary education}

The first stage of the process was to develop a succinct definition of flexible delivery that might serve to allay the fears of staff by focusing on the goal of meeting student needs, thus aligning staff and organizational goals. The focus on flexible delivery was intended to signal to the university community that the strategy was underpinned by a commitment to incremental rather than radical change. Hence the following definition was developed:

Flexible delivery refers to the use of a range of strategies and technologies to meet the diverse needs of students regarding the location and time of study. Flexible delivery is applicable to both internal and external students (QUT Office of the Deputy-ViceChancellor, 3 July 1998).

The Deputy-Vice-Chancellor's policy adviser, in consultation with key senior staff in the university, prepared a discussion paper that was widely circulated and then tabled as a policy document at Teaching and Learning Committee and then University Academic Board. A model of flexible delivery was subsequently developed as a framework within which policy and procedures could be determined. We reiterate that integral to the emphasis on flexible delivery was recognition that flexibility was merely the visible tip of a significant cultural change to the traditional university model. Figure 1 represents the framework. 


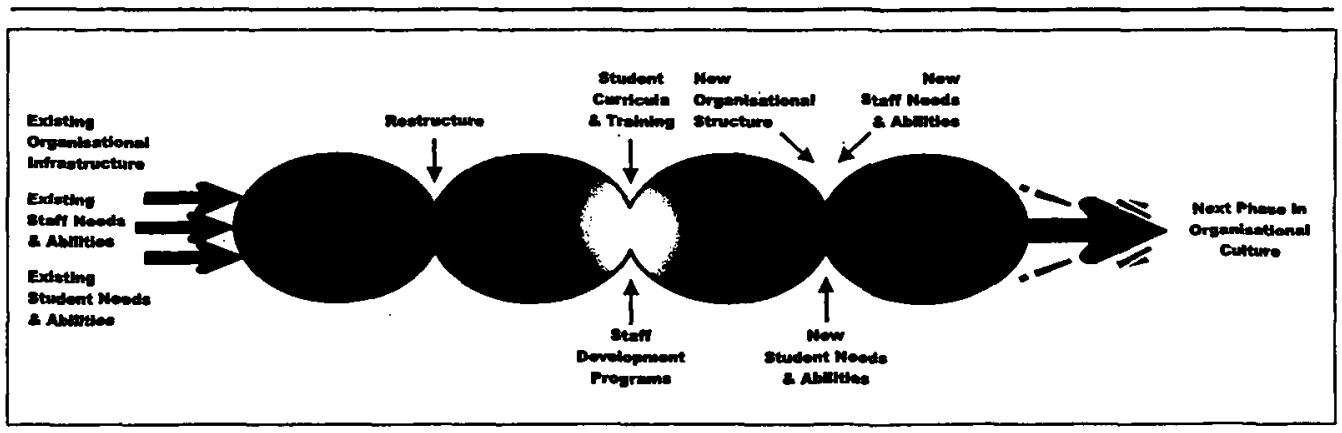

Figure 1: The flexible delivery framework

The structure signals that we see this model as requiring continuous adjustment, not to the extent of the changes of the last two years, but that the intersection of the ovals will always mean deliberate pressure on the organizational structure through management decisionmaking to support teaching and learning. We recognized that neither flexible learning nor flexible teaching can be mandated. Flexible learning depends on student needs and abilities. Flexible teaching rests on staff abilities such as discipline imperatives, commitment to quality teaching, knowledge of and confidence in using a range of technologies. However, we could, by 're-engineering' our systems and structures, nurture an organizational culture which valued 'learning about teaching and learning in a new context' as its primary goal.

\section{Principles of an organizational approach to flexible delivery}

Informing the model and the decisions consequent on the policy were several core principles:

- 'Flexibility' must be linked to specific learning objectives for each course and each subject, based on objective knowledge of student needs and the subject's rationale. While academic judgements regarding these objectives must be the final arbiter of the types of flexibility introduced, academics must also be fully informed of their students' emerging needs, and the potential of technology to assist them in enhancing learning.

- Student skills cannot be presumed in any pedagogic approach drawing on new technologies. Therefore, unlike the MIT Management for the 1990s Framework (Scott Morton, 1991), which focuses on strategy, structure, technology, management processes, and staff skills and roles, the QUT approach includes student skills and roles as a primary component.

- Collaborative approaches drawing on the expertise of academics, technical and learning support staff result in the best possible learning materials and teaching strategies.

- Staff development is embedded in the experience of actually developing flexible options.

- While individual academics must be encouraged to experiment and develop unique materials and strategies, sensible use of central resources means that investment must 
be largely directed in university-wide or faculty-wide initiatives which contribute to the organization as a whole.

- The 'learning organization' must demonstrate its commitment to whole-of-institution change by recognizing that university culture in particular is strongly individualistic and strongly decentralized. Hence support structures must balance the strengths of centralized units of expertise with the strengths of localized and semi-autonomous units of discipline and teaching knowledge.

- Full evaluation must be integrated in the design and development of all flexible delivery strategies and materials.

\section{Implementation}

Once the initial policy on flexible delivery was disseminated throughout the university, a number of activities and processes were undertaken progressively (not always, we should add, in a thoroughly planned way).

- A series of information sessions explicated the changing contexts of higher education, examples and demonstrations of flexible delivery within QUT and in other institutions, and how the administration was proposing to assist staff. These sessions were sponsored by the Senior Executive, thus ensuring that they had a high profile within the university community.

- The policy adviser to the Deputy-Vice-Chancellor undertook a data collection exercise to determine the extent of existing operational flexibility within the institution, and to focus on the variety of ways 'flexibility' could be perceived and implemented. Currently a more detailed pilot 'mapping' exercise is being undertaken within one faculty to understand better the impact of current initiatives and policy on the development of flexible practices, since we are convinced that information and staff consultation and input are vital to policy development. Changed practice can only result from a sound knowledge base.

- A series of commissioned divisional and departmental reviews over a two-year period from 1996 assessed the effectiveness of the central services supporting teaching and learning, identified potential cost savings and recommended structural changes to improve service provision. A three-staged restructuring process was implemented to forge synergies across previously separate units and ensure a more focused service. The resultant department is a large central unit, Teaching and Learning Support Services, providing a broad range of technical, professional and pedagogical expertise to staff and students.

- A drop-in centre, staffed part-time, was established and featured learning resources that capitalized on technological advances such as data visualization and the range of commercial CD-ROMs available, in a threat-free informal environment outside the formal training programme.

- Since 1992, QUT has provided funding for innovative teaching and learning projects. An internal evaluation of the grant scheme, following an earlier external evaluation, was designed to ensure a closer alignment between the projects funded and strategic 
university initiatives. The most important result has been our 'large grants', which provide funding up to $\$ 150,000$ over two years, for projects which embed flexible delivery practices across a faculty, or between faculties. Projects must have the support of the relevant dean or deans.

- Two extensive reports were commissioned from QUT staff with a knowledge of the existing orgainizational culture; one examined the pedagogical dimensions of the new technologies (Rossiter, 1997), the other evaluated existing computer-assisted learning at QUT (Wilss, 1997). The intention was to inform decision-making relating to the contribution that technology could make to increase flexibility.

- The Division invested in infrastructure and initiatives which demonstrated to staff the central commitment to extending flexibility. Among these was a combined student help desk, the student computing guide and the continued development of Datawarehouse as a teaching and learning vehicle as well as a management information system.

- A Web site, 'Teaching and Learning on the Internet', dedicated to teaching with technology in various forms, was established with easy-to-use features, an inviting interface, and links to QUT and international exemplars.

- Specialist positions at senior levels were identified and have progressively been filled with staff who combine both academic and technical expertise; the present authors are respectively at professorial and senior policy adviser (educational media and flexible delivery) levels.

\section{Lessons learned}

The key lessons we have learned from the processes and initiatives described above might prove useful to other institutions seeking to avoid wasteful pilot projects and 'wheel reinvention'.

- The visible and energetic support of senior management is critical to any strategic initiative involving cultural change and new approaches to teaching and learning. One of our successful faculties in 1998 admitted that had it not been for the criterion that their proposal for a grant must address flexibility, they would not have had to reexamine the nature of their curriculum and their students' expressed needs, and hence would not have realized how dated their teaching had become.

- Notwithstanding early resistance to the notion of uniting the academic and educational technology support units, it became obvious that unless management 'forced' the issue through amalgamation, the organizational culture would continue to be dichotomized between the 'techos' and the teachers. The resultant unit is a team of general and academic staff who bring their respective skills to catalyse flexible delivery initiatives across and within disciplines and faculty units. The renamed and restructured division (the Division of Information and Academic Services) has activated a high-profile promotion of its staff development activities to complement its existing reputation as a provider of technical and library services.

- Publicizing the successes (and failures) of initiatives through the university avoids ad hoc and sporadic small projects which are not sustainable. Workshops, seminars, 
newsletters, Web discussion groups, training programmes are all vital in this process. The variety of information modes acknowledges the diverse learning approaches of staff and students, and models flexibility.

- Notwithstanding the energy and commitment of the part-time staff member appointed, the drop-in centre was not as successful as we had expected. We surmise that this reflected its part-time status, its confinement to one campus, and the initial attitude of staff.

- The eariy data collection exercises revealed that 'flexibility' was not clearly and widely understood among staff: for example, many academics reported that they used presentation software such as PowerPoint, with no apparent recognition that computer-developed overheads, of themselves, do not imply flexibility. In order to be used flexibly, overheads must be available on the Web or placed in the library for student access independent of the lecture context in which they are delivered. Such information has informed our staff development activities.

- Restructuring organizations, particularly universities, with their fierce defence of territories, is not without pain for many individuals. Tempering fear and reworking job responsibilities, promoting team responsibility and collaboration while maintaining morale, demand time-consuming negotiation processes which require sensitivity on the part of senior management. Accurate and timely information and communication, we have found, assist to dispel the atmosphere of distrust which can easily arise.

\section{Conclusion}

There is no single template for organizational and cultural change within a university, anymore than there is a single template for online delivery. QUT has taken the view that far from inducing cataclysmic change in the shape of universities, the new technologies offer an opportunity for evolutionary development in approaches to teaching and learning, which can accommodate student and staff needs and abilities. That view is informed by a belief that learning in organizations is a continuous and evolving process, and that focusing on the purpose of the university, learning itself, we can develop appropriate institutional responses.

\section{References}

Bates, A. (1995), Technology, Open Learning and Distance Education, London: Routledge.

Cunningham, S., Tapsall, S., Ryan, Y., Stedman, L., Bagdon, K. and Flew, T. (1998), New Media and Borderless Education, Canberra: Australian Government Publishing Service.

Hart, G., Ryan, Y., Williams, H. and Lunney, P. (1998), Improving the Practice of Mental Health Nursing in Rural and Remote Communities, A Report for the Rural Health Support, Education and Training Program of the Commonwealth Department of Human Services and Health, Canberra.

Mason, R. (1998), Globalising Education: Trends and Applications, London and New York: Routledge. 
Oblinger, D. and Rush, S. (eds.) (1997), The Learning Revolution: The Challenges of Information Technology in the Academy, Bolton, MA: Anker.

Rossiter, D. (1997), The Digital Edge: Teaching and Learning in the Knowledge Age, Brisbane: QUT.

Saul, J. R. (1997), The Unconscious Civilization, Ringwood: Penguin.

Scott Morton, S. (ed.) (1991), The Corporation of the 1990s: Information Technology and Organizational Transformation, New York: Oxford University Press.

'Teaching and Learning on the Internet', http://www.tals.dis.qut.edu.au/tlow/tlow.htm.

Tiffin, J. and Rajasingham, L. (1995), In Search of the Virtual Class: Education in an Information Society, London: Routledge.

Wilss, L. (1997), Computer Assisted Learning at Queensland University of Technology: Student Learning Process and Outcomes, Brisbane: QUT. 